\title{
Milho grão seco ou úmido com sais de cálcio de ácidos graxos para novilhos Nelore em confinamento ${ }^{1}$
}

\section{Saulo da Luz e Silva ${ }^{2}$, Paulo Roberto Leme ${ }^{3}$, Soraia Marques Putrino ${ }^{4}$, Amaury Camilo Valinote $^{5}$, José Carlos Machado Nogueira Filho ${ }^{6}$, Dante Pazzanese Duarte Lanna ${ }^{7}$}

1 Projeto financiado pela Fapesp.

2 Pós-Doutorando (Bolsista FAPESP), FZEA/USP, Pirassununga, SP.

${ }^{3}$ FZEA/USP, Cx.P. 23, CEP: 13630-970, Pirassununga, SP

4 Doutora em zootecnia, FZEA/USP, Pirassununga, SP.

5 Pós-graduando, FZEA/USP, Pirassununga, SP.

RESUMO - Objetivou-se com este trabalho avaliar os efeitos do milho grão seco ou úmido e dos sais de cálcio de ácidos graxos no desempenho e nas características de carcaça de novilhos Nelore confinados na fase de terminação. Quarenta e oito animais com peso inicial de $431 \pm 29,8 \mathrm{~kg}$ foram alimentados durante 70 dias com uma das seguintes dietas: MGS - dieta basal composta de silagem de milho (40\%), milho grão seco $(48,4 \%)$, farelo de soja (7,6\%), uréia, sufato de amônia, cloreto de potássio, sal mineral, rúmen tamponante e rumensina (4\%); MGU - dieta basal, com substituição do MGS por milho grão úmido; MGS-SCAG - dieta basal contendo 45\% de MGS e 4\% de sais de cálcio de ácidos graxos; MGU-SCAG - dieta basal com 45\% de milho grão úmido e $4 \%$ de sais de cálcio de ácidos graxos. O ganho médio diário não foi influenciado pelo tipo de grão de milho, no entanto, a ingestão de MS pelos animais da dieta MGU foi menor que naqueles alimentados com a dieta MGS e resultou em maior eficiência alimentar para a dieta MGU. O maior número de protozoários ciliados ruminais foi observado nos animais alimentados com a dieta MGU. O rendimento de carcaça, a gordura renal pélvica e inguinal e a espessura de gordura subcutânea foram maiores nos animais alimentados com a dieta MGS. O ganho de peso médio diário também não diferiu entre os animais tratados ou não com SCAG, no entanto, a ingestão de MS foi maior nos animais alimentados com a dieta SCAG. Não houve influência sobre a eficiência alimentar. O número de protozoários ruminais foi menor nos animais alimentados com as dietas contendo SCAG, no entanto, as características de carcaça não foram influenciadas por essa dieta.

Palavras-chave: bovinos de corte, características de carcaça, desempenho em confinamento, gordura vegetal protegida, milho úmido ensilado

\section{Dry or high moisture corn grains and calcium salts of fatty acids for feedlot Nellore steers}

\begin{abstract}
The aim of this work was to evaluate the effects of dry corn grain or high moisture corn and calcium salts of fat acids on the performance and carcass traits of feedlot fed Nellore steers on finishing phase. Forty eight animals with $431 \pm 29.8 \mathrm{~kg}$ of initial mean body weight were fed during 70 days, with one of the four diets: MGS - basal diet containing corn silage $(40 \%)$, dry corn grain $(48.4 \%)$, soybean meal $(7.6 \%)$, urea, amonium sulphate, mineral salt, limestone and monensin (4\%); MGU - basal diet with high moisture corn replacing MGS; MGS-SCAG - basal diet with $45 \%$ of MGU and $4 \%$ of calcium salts of fatty acids; MGU-SCAG - basal diet with $45 \%$ of MGS and $4 \%$ of calcium salts of fatty acids. The average daily gain was not affected by grain type. However, dry matter intake of animals of MGU treatment was smaller than MGS treatment, with a greater feed efficiency for MGU treatment. A greater number of ruminal ciliate protozoa was found in MGU treatments. Dressing percentage, renal, pelvic and inguinal fat and backfat thickness were greater in animals fed MGS diet. Average daily gain was not different between animals fed with or without SCAG, although, dry matter intake was greater in diets with SCAG, with no effect on feed efficiency. Protozoa number was smaller in diets containing SCAG and carcass traits were not affected by SCAG.
\end{abstract}

Key Words: beef cattle, corn grain processing, carcass traits, feedlot performance, protected vegetable fat

\section{Introdução}

O fornecimento de dietas com elevado teor de concentrado para bovinos jovens, que apresentam boa resposta a esse tipo de alimentação, tem sido adotado com o objetivo de intensificar o sistema de produção, pois permite o abate de animais jovens com acabamento de gordura adequado, sem prejuízos à qualidade da carne (Leme et al. 
2003). No entanto, especialmente em relação à zebuínos, é possível observar respostas inconsistentes quando são submetidos a dietas nas quais o amido responde por mais de $50 \%$ da MS ou o teor de NDT excede $67 \%$, o que dificulta a utilização de dietas com alta energia (Lanna, 1998).

O aumento da disponibilidade de energia da dieta sem aumento do teor de concentrado pode ser obtido pelo processamento do grão, que aumenta a disponibilidade do amido para digestão.

Grãos colhidos precocemente (30\% de umidade) e armazenados em condições anaeróbicas apresentam uma maiores digestibilidades in vitro e in vivo em comparação a grãos secos (Hibberd et al., 1985; Streeter et al., 1989), sugerindo que o maior teor de umidade favorece a fermentação no interior do silo, resultando em maior solubilização dos nutrientes e melhora da digestibilidade e, conseqüentemente, aumentando o valor alimentar do grão (Simas, 1997). A utilização do milho úmido também apresenta outras vantagens, como minimização das perdas na colheita, menor tempo de ocupação da área plantada, redução dos custos e do tempo gastos com o processo de secagem, entre outros (Henrique et al., 1999).

Owens et al. (1997) compararam os resultados de 419 trabalhos envolvendo mais de 16 mil animais e verificaram que animais tratados com milho grão úmido ganharam menos peso $(5,5 \%)$ e reduziram a ingestão de $\operatorname{MS}(7,7 \%)$, mas foram mais eficientes ( $2 \%$ ) que os tratados com milho grão seco. De acordo com esses autores, o maior processamento do grão causa pequena redução no ganho de peso, que pode ser atribuída à redução na ingestão de MS. Essa menor ingestão de grãos rapidamente fermentescíveis no rúmen pode ser decorrente do excesso de produção de ácidos e acidose subclínica, o que aumenta as variações diárias de consumo.

Gorduras e óleos têm sido utilizados na alimentação de ruminantes em substituição a altas proporções de grãos, com o intuito de aumentar a densidade energética da dieta, aumentar a eficiência alimentar, além de garantir a ingestão de fibra necessária para o bom funcionamento do rúmen (Valinote et al., 2005). De acordo com Palmquist (1984), a importância da gordura na produção de bovinos tende a receber menor ênfase que outros nutrientes como proteína, fibra, minerais e vitaminas. No entanto, a gordura possui importantes qualidades para as dietas por ser uma fonte densa de energia e de ácidos graxos essenciais, aumentando a absorção de vitaminas lipossolúveis e a eficiência energética.

Por outro lado, a adição de gordura pode causar impacto negativo na fermentação ruminal e na digestão das fibras, além de ocasionar problemas metabólicos, uma vez que inibe o crescimento e metabolismo dos microrganismos ruminais pela ação dos ácidos graxos de cadeia longa (Henderson, 1973).

Segundo Haaland et al. (1981), dietas contendo mais de $5 \%$ de gordura não protegida da degradação ruminal reduzem a ingestão de alimento, prejudicando o desempenho de animais em crescimento e terminação. Entretanto, as gorduras protegidas, também conhecidas como inertes, contêm 80 a 99\% de lipídeos e podem escapar da fermentação ruminal (Chalupa et al., 1986) não atuando de forma negativa na digestão das paredes celulares das forragens no rúmen (Schauff \& Clark, 1989), além de serem de fácil manuseio e possuírem um período de conservação maior que o das gorduras não protegidas.

Os sais de cálcio de ácidos graxos são gorduras insolúveis no rúmen, onde o pH é mais elevado, e solúveis no abomaso, onde o pHé ácido. Chalupa et al. (1986) observam que valores de $\mathrm{pH}$ ruminal inferiores a 6,0 podem causar dissociação desse complexo no rúmen, liberando ácidos graxos livres, que, em níveis elevados, têm efeito tóxico sobre algumas bactérias e protozoários ruminais.

Há pouca informação disponível sobre os efeitos dos lipídeos protegidos na alimentação de bovinos de corte e seus efeitos sobre o desempenho e a composição da carcaça. Garret et al. (1976), observaram melhora na qualidade da carne quando óleos vegetais protegidos da degradação ruminal foram oferecidos a bovinos em terminação. Ngidi et al. (1990) relataram que o aumento do nível de gordura protegida na ração causou redução na ingestão de MS e no ganho de peso, enquanto a eficiência alimentar tendeu a aumentar com a adição da gordura.

Desse modo, objetivou-se com este trabalho avaliar o efeito do fornecimento de dietas contendo milho grão seco ou milho grão úmido, com ou sem sais de cálcio de ácidos graxos, sobre o desempenho e as características de carcaça de novilhos Nelore em confinamento na fase de terminação.

\section{Material e Métodos}

Quarenta e oito novilhos da raça Nelore provenientes do rebanho da Prefeitura do Campus Administrativo da USP de Pirassununga, recriados a pasto e com peso médio no início do período de adaptação de $409 \mathrm{~kg}$ e média de 36 meses de idade, foram distribuídos em quatro piquetes, em delineamento experimental inteiramente casualizado, em arranjo fatorial $2 \times 2$, com quatro tratamentos (dietas) e 12 repetições. Cada piquete era equipado com portões eletrônicos (Calan Gates) que limitam o acesso de cada animal a um único cocho, permitido o controle individual de consumo de diferentes dietas para animais do mesmo piquete. 
Os animais foram alimentados com quatro dietas: MGS - dieta basal contendo milho grão seco; MGU - dieta basal com substituição do MGS por milho grão úmido; MGS-SCAG - dieta basal com MGS e 4\% de sais de cálcio de ácidos graxos (Lactoplus®; Dalquim IndústriaQuímica Ltda, Itajaí, SC, Brasil); MGU-SCAG - dieta basal com MGU e 4\% de sais de cálcio de ácidos graxos (Tabela 1). As dietas foram balanceadas utilizando-se o software RLM® (Escola Superior de Agricultura Luiz de Queiroz, Piracicaba, SP, Brasil). Para o cálculo das exigências nutricionais, foi utilizado o sistema Cornell Net Carbohidrate and Protein System - CNCPS (Fox et al., 1992).

O MGU foi colhido quando o grão estava com $30 \%$ de umidade e foi triturado em moinho tipo martelo e armazenado em silo trincheira.

Diariamente, a silagem de milho e o concentrado foram pesados separadamente, misturados e oferecidos aos animais de acordo com a dieta pré-determinada. A cada dois dias, foi retirada, pesada e determinada a MS das sobras para realização do ajuste no total de alimento a ser oferecido no dia seguinte e para o cálculo da MS ingerida. A oferta de alimento foi determinada com base no consumo de MS dos animais somado a $10 \%$ para que houvesse sobra do total de alimento oferecido.
Os animais foram pesados na chegada ao confinamento, após jejum completo de aproximadamente 18 horas e, posteriormente, em intervalos de 28 dias. Um animal apresentou problemas de adaptação e foi retirado do experimento.

Após 70 dias em confinamento, os animais foram abatidos quando a média da espessura de gordura subcutânea medida por ultra-sonografia atingiu cerca de $7 \mathrm{~mm}$. Durante o abate, foram obtidos os pesos da carcaça quente (PCQ), das gorduras renal, pélvica e inguinal (GRPI) e do fígado (FIG) e o rendimento de carcaça (RC).

Imediatamente após o abate e a evisceração, foram coletadas amostras de líquido ruminal de quatro animais de cada dieta para identificar e quantificar os principais gêneros de protozoários ciliados no rúmen. O conteúdo ruminal foi retirado através de uma incisão na parte ventral do rúmen, sendo homogeneizado e amostrado manualmente. Uma alíquota de $10 \mathrm{~mL}$ de líquido ruminal foi transferida para frascos de vidro com $10 \mathrm{~mL}$ de formaldeído a $37 \%$. As amostras foram mantidas em repouso até o momento das determinações, realizadas conforme metodologia de Dehority (1977), utilizando-se câmara de contagem de Sedgwick-Rafter com capacidade de $1 \mathrm{~mL}$ e microscópio ótico comum provido de retículo com área de $0,4362 \mathrm{~mm}^{2}$.

Tabela 1 - Composição percentual das dietas milho grão seco (MGS), milho grão úmido (MGU), MGS com sais de cálcio de ácidos graxos (MGS-SCAG) e MGU com sais de cálcio de ácidos graxos (MGU-SCAG)

Table 1 - Percentage composition of diets dry corn grain (MGS), high moisture corn (MGU), MGS and calcium salts of fatty acids (MGS-SCAG) and MGU and calcium salts of fatty acids (MGU-SCAG)

\begin{tabular}{|c|c|c|c|c|}
\hline \multirow{3}{*}{$\begin{array}{l}\text { Ingrediente } \\
\text { Ingredient }\end{array}$} & \multirow{2}{*}{\multicolumn{4}{|c|}{$\begin{array}{l}\text { Dieta } \\
\text { Diet }\end{array}$}} \\
\hline & & & & \\
\hline & MGS & MGU & MGS-SCAG & MGU-SCAG \\
\hline Silagem de milho (Corn silage) & 40,0 & 40,0 & 40,0 & 40,0 \\
\hline Farelo de soja (49\%) (Soybean meal) & 7,63 & 7,63 & 7,63 & 7,63 \\
\hline Milho grão seco moído (Ground dry corn) & 48,44 & - & 45,04 & - \\
\hline Milho grão úmido (High moisture corn) & - & 48,44 & - & 45,04 \\
\hline Uréia (Urea) & 0,97 & 0,97 & 0,97 & 0,97 \\
\hline Sulfato de amônia (Amonium sulphate) & 0,06 & 0,06 & 0,06 & 0,06 \\
\hline Cloreto de potássio (Potassium chloride) & 0,40 & 0,40 & 0,40 & 0,40 \\
\hline Sal mineral (Mineral premix) & 0,40 & 0,40 & 0,40 & 0,40 \\
\hline Calcário (Limestone) & 0,60 & 0,60 & - & - \\
\hline Rúmen tamponante ${ }^{2}$ (Rumen buffer) & 1,50 & 1,50 & 1,50 & 1,50 \\
\hline Rumensina $^{\circledR} 3$ (Rumensin $^{\circledR}$ ) & 0,027 & 0,027 & 0,027 & 0,027 \\
\hline \multicolumn{5}{|l|}{$\begin{array}{l}\text { Nutriente, } \%^{3} \\
\text { Nutrient }\end{array}$} \\
\hline $\operatorname{NDT}(T D N)$ & 74,01 & 74,01 & 78,22 & 78,22 \\
\hline $\mathrm{PB}(C P)$ & 14,25 & 14,25 & 13,92 & 13,92 \\
\hline $\mathrm{EE}$ & 3,44 & 3,44 & 6,57 & 6,57 \\
\hline $\mathrm{Ca}$ & 0,41 & 0,41 & 0,61 & 0,61 \\
\hline $\mathrm{P}$ & 0,34 & 0,34 & 0,33 & 0,33 \\
\hline
\end{tabular}

1 Sais de cálcio de ácidos graxos (Dalquim Indústria Química Ltda, Itajaí, SC, Brasil) (Calcium salts of fatty acid, Dalquin Ind. Química Ltda).

2 Premix ${ }^{\circledR}$ bicarbonato de sódio $20 \%$ e óxido de magnésio $2,3 \%$ (Premix® sodium bicarbonate $20 \%$ and magnesium oxide $2.3 \%$ ).

3 Elanco Animal Health, Greenfield, IN, USA.

${ }^{4}$ Estimado pelo programa RLM - ESALQ/USP (Estimated by RLM program - ESALQ/USP). 
Após 24 horas de resfriamento $\left(0\right.$ a $\left.2^{\circ} \mathrm{C}\right)$, foi determinado o $\mathrm{pH}(\mathrm{pH} 24)$ nas meias-carcaças esquerdas, que, em seguida, foram seccionadas entre a $12 \underline{a}$ e a $13 \underline{a}$ costelas para obtenção da área de olho-de-lombo, em cm² (AOL), e da espessura de gordura subcutânea, em mm (EGS), com auxílio de uma grade reticulada com escala em $\mathrm{cm}^{2}$, especial para esta finalidade.

Após determinação da AOL e EGS, foram retiradas três amostras de aproximadamente $2,5 \mathrm{~cm}$ de espessura do músculo Longissimus (LM) na região entre a $11 \underline{\mathrm{a}}$ e a $12^{\underline{a}}$ costelas, embaladas a vácuo e maturadas por 0,7 ou 14 dias para determinação da força de cisalhamento, obtida pelo aparelho Warner Bratzler Shear Force, conforme metodologia descrita por AMSA (1995).

A análise dos efeitos principais e das interações foram realizadas pelo procedimento Mixed do software $\mathrm{SAS}^{\circledR}$ (SAS, 2001). As médias dos efeitos principais e das possíveis interações foram comparadas pelo teste F. O modelo estatístico utilizado é descrito abaixo.

$$
Y_{i j k}=\mu+M_{i}+S_{j}+M x S_{i j}+e_{i j k}
$$

em que: $Y_{i j k}=$ resposta observada no k-ésimo animal que recebeu o j-ésimo nível de SCAG e o i ésimo tipo de milho; $\mu=$ constante inerente a todas as observações; $M_{i}=$ efeito do i-ésimo de tipo de milho; $S_{j}=$ efeito do j-ésimo nível de SCAG; $\mathrm{MxS}_{\mathrm{ij}}=$ efeito da interação tipo de milho $\mathrm{i} \times$ nível de SCAG $\mathrm{j} ; \mathrm{e}_{\mathrm{ijk}}=$ efeito aleatório residual, associado ao k-ésimo animal, suposto NID $\left(0, \delta^{2}{ }_{\mathrm{e}}\right)$.

\section{Resultados e Discussão}

Não houve interação dos fatores estudados para nenhuma das características de desempenho avaliadas (Tabela 2). O peso vivo final e o ganho médio diário não foram influenciados pelo tipo de grão de milho (Tabela 3 ). A ingestão de MS foi maior nos animais alimentados com a dieta MGS em relação aos alimentados com MGU, tanto em $\mathrm{kg}(\mathrm{P}=0,0004)$ quanto em porcentagem do peso vivo $(\mathrm{P}=0,0064)$. Conseqüentemente, os animais alimentados com a dieta MGU apresentaram maior eficiência alimentar $(\mathrm{P}=0,0372)$ em comparação aos alimentados com MGS.

Resultados semelhantes ao observado neste estudo foram relatados por Henrique et al. (1999), que compararam o efeito de dietas com alto nível de concentrado, contendo milho úmido ou seco ( 58 a $67 \%$ de MS), sobre o desempenho e as características de carcaça de tourinhos Santa Gertrudis em confinamento. Esses autores não observaram efeito do tipo de grão sobre o consumo de alimento ou o ganho de peso, mas observaram melhor eficiência alimentar dos animais alimentados com milho úmido. Apesar da ausência de diferença estatística, os animais alimentados com milho úmido ingeriram 3,1\% menos alimento e ganharam $5,2 \%$ mais peso; foram, portanto, $5,3 \%$ mais eficientes.

Do mesmo modo, Ladely et al. (1995) observaram redução na ingestão de MS e aumento na eficiência alimentar,

Tabela 2 - Número de observações (N), médias, desvios-padrão (DP), mínimos e máximos das características avaliadas Table 2 - Number of observations $(N)$, means, standard deviations (SD), minimum and maximum values of the evaluated traits

\begin{tabular}{|c|c|c|c|c|c|}
\hline $\begin{array}{l}\text { Característica } \\
\text { Trait }\end{array}$ & $\mathrm{N}$ & $\begin{array}{l}\text { Média } \\
\text { Mean }\end{array}$ & $\begin{array}{l}\mathrm{DP} \\
S D\end{array}$ & $\begin{array}{l}\text { Mínimo } \\
\text { Minimum }\end{array}$ & $\begin{array}{l}\text { Máximo } \\
\text { Maximum }\end{array}$ \\
\hline Peso inicial, kg (Initial weight, $k g$ ) & 47 & 430 & 29,6 & 380 & 496 \\
\hline Ganho médio diário, kg/d (Average daily gain) & 47 & 1,39 & 0,29 & 0,66 & 1,88 \\
\hline MS ingerida, $\mathrm{kg} / \mathrm{d}$ (DM intake) & 47 & 9,5 & 2,1 & 5,9 & 13,1 \\
\hline MS ingerida, \% do peso (DM intake, \% of weight) & 47 & 2,0 & 0,4 & 1,1 & 2,9 \\
\hline Peso carcaça quente, $\mathrm{kg}$ (Hot carcass weight) & 47 & 293,2 & 24,3 & 251,5 & 355,9 \\
\hline Rendimento de carcaça, \% (Dressing percentage) & 47 & 55,6 & 1,5 & 52,9 & 59,8 \\
\hline Gordura renal, pélvica e inguinal, $\mathrm{kg}$ (Renal, pelvic and inguinal fat) & 47 & 15,8 & 3,6 & 6,9 & 24,9 \\
\hline Peso do fígado, $\mathrm{kg}$ (Liver weight) & 47 & 5,4 & 0,6 & 4,2 & 6,7 \\
\hline Área de olho-de-lombo, $\mathrm{cm}^{2}$ (Ribeye area) & 46 & 69,0 & 6,6 & 56,0 & 86,0 \\
\hline Espessura de gordura subcutânea, mm (Backfat thickness) & 46 & 7,5 & 2,0 & 3,0 & 12,0 \\
\hline pH 24 horas ( $p H 24$ hours) & 46 & 5,66 & 0,17 & 5,3 & 6,1 \\
\hline Perdas por cocção dia $0, \%$ (Cooking losses day 0 ) & 47 & 19,9 & 6,21 & 9,9 & 31,2 \\
\hline Perdas por cocção dia 7, \% (Cooking losses day 7) & 47 & 23,0 & 5,9 & 9,0 & 35,8 \\
\hline Força de cisalhamento dia $7, \mathrm{~kg}$ (Shear force day 7 ) & 47 & 3,7 & 1,0 & 1,9 & 5,9 \\
\hline Perdas por cocção dia 14, \% (Cooking losses day 14) & 47 & 25,1 & 4,8 & 12,3 & 34,4 \\
\hline Força de cisalhamento dia $14, \mathrm{~kg}$ (Shearforce day 14 ) & 47 & 3,0 & 0,7 & 1,7 & 4,4 \\
\hline
\end{tabular}

${ }^{1} \mathrm{MS}$ ingerida/ganho médio diário (DM intake/average daily gain). 
Tabela 3 - Características de desempenho de animais alimentados com dietas contendo milho grão seco (MGS), milho grão úmido (MGU), com ou sem sais de cálcio de ácidos graxos (SCAG)

Table 3 - Performance traits of animals fed dry corn grain (MGS), high moisture corn grain (MGU) with or without calcium salts of fatty acids (SCAG)

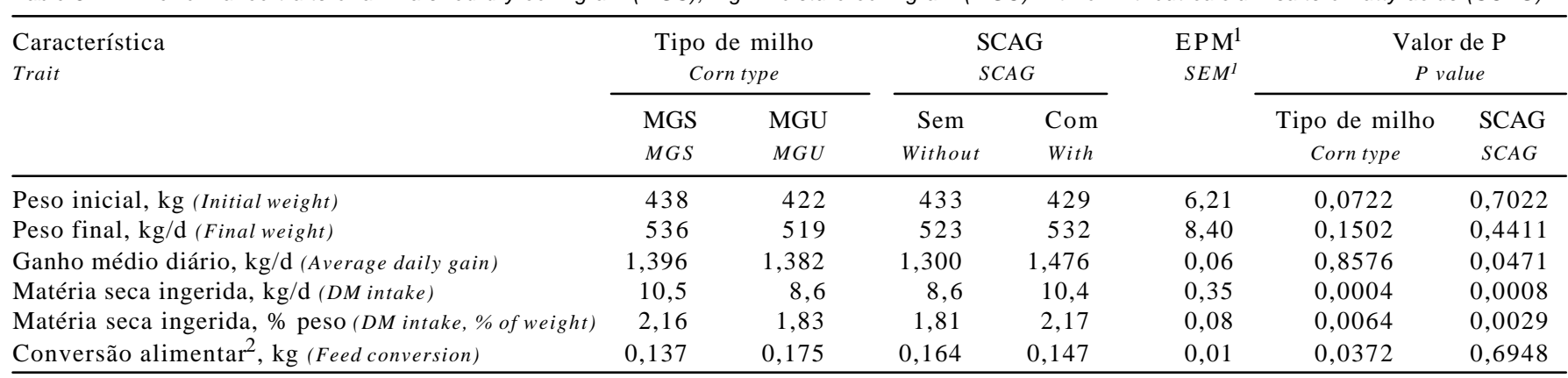

${ }^{1}$ Erro-padrão da média (Standard error of mean).

${ }^{2} \mathrm{MS}$ ingerida/ganho médio diário (DM intake/average daily gain).

sem alteração do ganho de peso, em novilhos e novilhas alimentados com dietas contendo milho úmido em relação a dietas contendo milho seco.

Stock et al. (1991) testaram o efeito da umidade (27,2; 27,6 e 37,6) e do tipo de armazenamento ( silo) do milho grão úmido, em comparação ao milho ou ao sorgo grão seco ou combinações de sorgo e milho úmido. De acordo com esses autores, não houve efeito significativo entre a média das dietas contendo MGU em relação ao MGS quanto à ingestão de MS, ao ganho de peso ou à eficiência alimentar, no entanto, houve tendência de maior digestibilidade das dietas contendo MGU em relação ao MGS.

Apesar de o ganho de peso médio diário dos animais não ter diferido estatisticamente, os animais alimentados com dietas contendo milho úmido consumiram $18 \%$ menos MS, quando expressa em $\mathrm{kg}$, e 15,7\%, quando expressa na porcentagem do peso vivo; foram, portanto, $18 \%$ mais eficientes.

Não houve efeito significativo da interação dos fatores testados sobre o número de protozoários ciliados ruminais (Tabela 4 ). Os animais alimentados com dietas contendo MGU apresentaram maior número de Entodinium $(\mathrm{P}<0,0001)$ e Eudiplodinium $(\mathrm{P}=0,0507)$, bem como maior número total de protozoários $(\mathrm{P}<0,0001)$, o que pode ser atribuído à maior disponibilidade ruminal de amido nessas dietas.

Esses resultados estão de acordo com os relatados por Mendoza et al. (1999), que observaram maior concentração de Entodinium em animais alimentados com dietas contendo uma combinação de $67 \%$ MGU e $33 \%$ de grão de sorgo seco. Segundo esses autores, protozoários desse gênero podem ser estimulados pelo aumento da quantidade de amido rapidamente fermentável em dietas contendo MGU, até determinado ponto, uma vez que condições ácidas podem influenciá-los negativamente.
O maior número de protozoários ruminais nas dietas MGU pode ser considerado indicativo de uma condição ruminal adequada, que permitiu o crescimento e/ou o desenvolvimento dos microrganismos ruminais. Maior degradabilidade ruminal das dietas contendo MGU poderia causar redução do $\mathrm{pH}$ e, conseqüentemente, ter efeito negativo sobre os protozoários ruminais, o que, no entanto, não parece ter ocorrido, uma vez que a população de protozoários ruminais aparentemente não foi influenciada negativamente. $\mathrm{O}$ fato de os protozoários reduzirem o grau e a taxa de digestão do amido no rúmen com a ingestão e o armazenamento dos grânulos de amido pode ter reduzido a disponibilidade de amido no rúmen, evitando problemas metabólicos em decorrência de sua rápida degradação.

Os animais alimentados com a dieta MGS apresentaram maiores PCQ $(\mathrm{P}=0,0439), \mathrm{RC}(\mathrm{P}=0,0343)$ e GRPI $(\mathrm{P}=0,0151)$ em comparação àqueles alimentados com a dieta MGU. O FIG não foi influenciado pelo tipo de grão (Tabela 5).

Houve efeito $(\mathrm{P}=0,0457)$ da interação das dietas sobre a AOL. A área de olho-de-lombo dos animais alimentados com a dieta MGS foi menor $(\mathrm{P}=0,0196)$ que a dos alimentados com MGS-SCAG $\left(67,4\right.$ e 73,9 $\mathrm{cm}^{2}$, respectivamente), enquanto os animais alimentados com a dieta MGS-SCAG apresentaram AOL maior $(\mathrm{P}=0,0156)$ que a daqueles alimentados com a dieta MGU-SCAG (73,9 e 67,2 $\mathrm{cm}^{2}$, respectivamente).

Também houve interação tipo de grão de milho x SCAG na EGS $(P=0,0047)$, que foi maior $(P=0,0408)$ nos animais alimentados com a dieta MGS-SCAG em relação a MGS $(7,4$ e 9,0 mm, respectivamente). Os animais alimentados com a dieta MGU apresentaram maior EGS $(\mathrm{P}=0,0406)$ em relação àqueles alimentados com a dieta MGU-SCAG (7,5 e 6,0 mm, respectivamente). Não houve diferença entre as dietas MGU e MGS (7,4 e 7,4 mm, respectivamente) quanto à EGS. No entanto, nos animais alimentados com a MGS-SCAG, a 
Tabela 4 - Médias de protozoários ciliados do rúmen (x104) por gênero e total dos animais alimentados com milho grão seco (MGS) ou milho grão úmido (MGU), com ou sem sais de cálcio de ácidos graxos (SCAG)

Table 4 - Means of rumen ciliate protozoa $\left(\times 10^{4}\right)$ by genus and total of animals fed dry corn grain (MGS), high moisture corn grain (MGU) with or without calcium salts of fatty acids (SCAG)

\begin{tabular}{|c|c|c|c|c|c|c|c|}
\hline \multirow[t]{2}{*}{$\begin{array}{l}\text { Protozoários } \\
\text { Protozoa }\end{array}$} & \multicolumn{2}{|c|}{$\begin{array}{l}\text { Tipo de milho } \\
\text { Corn type }\end{array}$} & \multicolumn{2}{|c|}{$\begin{array}{l}\text { SCAG } \\
\text { SCAG }\end{array}$} & \multirow[t]{2}{*}{$\begin{array}{c}\mathrm{EPM}^{1} \\
S E M^{l}\end{array}$} & \multicolumn{2}{|c|}{$\begin{array}{c}\text { Valor de } \mathrm{P} \\
P \text { value }\end{array}$} \\
\hline & $\begin{array}{l}\text { MGS } \\
M G S\end{array}$ & $\begin{array}{l}\text { MGU } \\
M G U\end{array}$ & $\begin{array}{c}\text { Sem } \\
\text { Without }\end{array}$ & $\begin{array}{l}\text { Com } \\
\text { With }\end{array}$ & & $\begin{array}{l}\text { Tipo de milho } \\
\text { Corn type }\end{array}$ & $\begin{array}{l}\text { SCAG } \\
S C A G\end{array}$ \\
\hline Entodinium & 32,1 & 78,0 & 63,5 & 46,6 & 8,86 & $<0,0001$ & 0,5799 \\
\hline Diplodinium & 2,5 & 3,3 & 4,3 & 1,6 & 0,40 & 0,1661 & 0,0005 \\
\hline Epidinium & 2,9 & 3,3 & 3,7 & 2,6 & 3,62 & 0,6367 & 0,2049 \\
\hline Isotricha & 2,1 & 1,7 & 1,8 & 2,0 & 1,89 & 0,1773 & 0,6992 \\
\hline Eudiplodinium & 1,5 & 2,0 & 1,6 & 1,9 & 0,15 & 0,0507 & 0,1183 \\
\hline Total & 41,3 & 88,4 & 75,0 & 54,7 & 7,95 & $<0,0001$ & 0,0257 \\
\hline
\end{tabular}

1 Erro-padrão da média (Standard error of mean).

Tabela 5 - Características de carcaça dos animais alimentados com milho grão seco (MGS) ou milho grão úmido (MGU), com ou sem sais de cálcio de ácidos graxos (SCAG)

Table 5 - Carcass traits of animals fed dry corn grain (MGS), high moisture corn grain (MGU) with or without calcium salts of fatty acids (SCAG)

\begin{tabular}{|c|c|c|c|c|c|c|c|}
\hline \multirow[t]{2}{*}{$\begin{array}{l}\text { Característica } \\
\text { Trait }\end{array}$} & \multicolumn{2}{|c|}{$\begin{array}{l}\text { Tipo de milho } \\
\text { Corn type }\end{array}$} & \multicolumn{2}{|c|}{$\begin{array}{l}\text { SCAG } \\
S C A G\end{array}$} & \multirow[t]{2}{*}{$\begin{array}{c}\mathrm{EPM}^{1} \\
S E M^{1}\end{array}$} & \multicolumn{2}{|c|}{$\begin{array}{c}\text { Valor de } \mathrm{P} \\
P \text { value }\end{array}$} \\
\hline & $\begin{array}{l}\text { MGS } \\
M G S\end{array}$ & $\begin{array}{l}\mathrm{MGU} \\
M G U\end{array}$ & $\begin{array}{c}\text { Sem } \\
\text { Without }\end{array}$ & $\begin{array}{l}\text { Com } \\
\text { With }\end{array}$ & & $\begin{array}{l}\text { Tipo de milho } \\
\text { Corn type }\end{array}$ & $\begin{array}{l}\text { SCAG } \\
\text { SCAG }\end{array}$ \\
\hline Peso carcaça quente, $\mathrm{kg}$ (Hot carcass weight) & 300 & 286 & 289 & 298 & 4,93 & 0,0439 & 0,2272 \\
\hline Rendimento de carcaça, \% (Dressing percentage) & 56,1 & 55,1 & 55,3 & 55,9 & 0,31 & 0,0343 & 0,1364 \\
\hline $\mathrm{GRPI}^{2}, \mathrm{~kg}(G R P I)$ & 17,1 & 14,6 & 15,1 & 16,5 & 0,71 & 0,0151 & 0,1684 \\
\hline Peso do fígado, $\mathrm{kg}$ (Liver weight) & 5,4 & 5,4 & 5,3 & 5,5 & 0,13 & 0,8300 & 0,3191 \\
\hline Área de olho-de-lombo, $\mathrm{cm}^{2}$ (Ribeye area) & 70,7 & 67,8 & 67,9 & 70,5 & 1,31 & 0,1281 & 0,1635 \\
\hline $\mathrm{EGS}^{3}, \mathrm{~mm}(E G S)$ & 8,2 & 6,8 & 7,5 & 7,5 & 0,37 & 0,0090 & 0,9713 \\
\hline pH 24 horas ( $p H 24$ hours) & 5,6 & 5,7 & 5,7 & 5,6 & 0,03 & 0,2775 & 0,0341 \\
\hline
\end{tabular}

${ }^{1}$ Erro-padrão da média (Standard error of mean).

2 Gordura renal, pélvica e inguinal (Kidney, pelvic and inguinal fat).

${ }^{3}$ Espessura de gordura subcutânea (Backfat thickness).

EGS foi maior $(P=0,0003)$ que naqueles das dietas MGUSCAG (9,0 e 6,0 mm, respectivamente).

Resultados semelhantes foram relatados por Henrique et al. (1999), que não observaram efeito do tipo de grão de milho sobre as características de carcaça, exceto o peso do fígado, que foi maior nos animais alimentados com milho úmido. Por outro lado, Stock et al. (1987) verificaram menor EGS nos animais alimentados com milho úmido e observaram que a AOL e a classificação da carcaça não foram alteradas em comparação à obtida com a dieta contendo milho seco.

Scott et al. (2003) também não observaram diferenças no "quality grade", AOL ou EGS, de novilhos alimentados com milho seco ou com uma combinação de milho grão úmido e glúten úmido de milho.Do mesmo modo,Ladely et al. (1995) também não observaram diferenças na EGS e na qualidade da carcaça de novilhos alimentados com dietas contendo MGU ou MGS. Owens et al. (1999), em revisão de literatura, verificaram que animais alimentados com dietas contendo MGU apresentaram maior AOLe EGS, porém, não diferiram quanto ao marmoreio e à qualidade da carcaça se comparados ao alimentados com milho seco.

$\mathrm{O}$ pH analisado 24 horas após o abate foi maior nas carcaças dos animais $(\mathrm{P}=0,0341)$ alimentados com as dietas contendo MGU. A força de cisalhamento diminuiu $(\mathrm{P}<0,0001$; Figura 1), enquanto as perdas de água por cocção aumentaram ( $\mathrm{P}<0,0001$; Figura 2) linearmente com o tempo de maturação, mas não foram influenciadas pelas dietas.

Não houve efeito dos SCAG sobre o peso vivo final dos animais em comparação àqueles sem suplementação com SCAG. O ganho de peso médio diário não diferiu entre os animais alimentados ou não com dietas contendo SCAG. No entanto, a ingestão de MS expressa em $\mathrm{kg}$ ouem porcentagem do peso vivo foi maior $(\mathrm{P}=0,0008$ e $\mathrm{P}=0,0029$, respectivamente) nos animais alimentados com SCAG, mas não influenciou a eficiência alimentar.

A adição de SCAG na dieta de bovinos tem apresentado resultados variados em relação ao desempenho e às carac- 
terísticas de carcaça. Ngidi et al. (1990) estudaram o efeito da adição de níveis de SCAG (0, 2, 4 ou 6\%) em dietas com alta porcentagem de concentrado $(85 \%)$ para bovinos em fase de terminação e observaram redução linear na ingestão de MS e no ganho de peso conforme aumentou o nível de SCAG, mas não influenciou a eficiência alimentar. De acordo com os autores, a redução da ingestão deve ter ocorrido em virtude da pequena aceitabilidade dos sais de cálcio, dos controles quimiostático e lipostático da ingestão e do efeito depressivo sobre a motilidade ruminal causado pelos ácidos graxos de cadeia longa no duodeno.

Aferri et al. (2005) também analisaram o efeito da inclusão de $5 \%$ de SCAG $\left(\right.$ Lac $\left.100^{\circledR}\right)$ na dieta de novilhos em fase de terminação confinados por aproximadamente 70 diascom uma dieta contendo $81 \%$ de concentrado. Esses autores observaram que a inclusão de SCAG não influenciou signi-

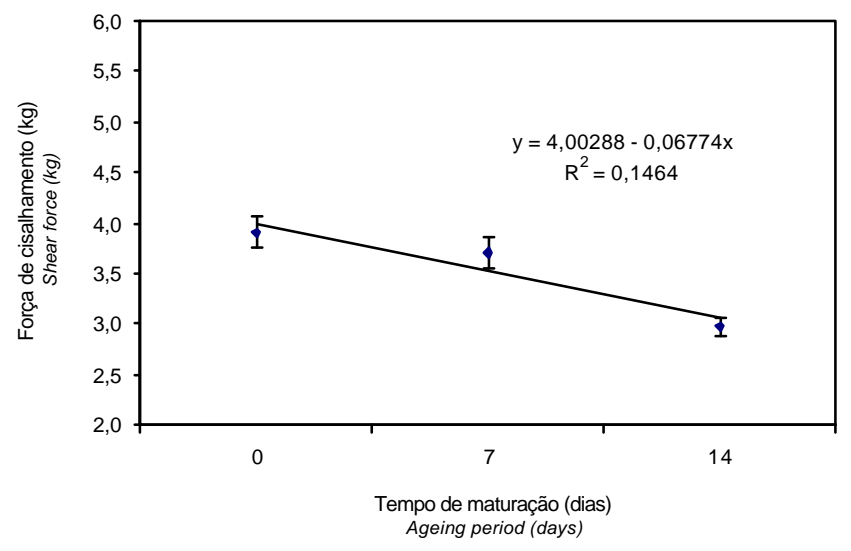

Figura 1 - Força de cisalhamento nos diferentes tempos de maturação.

Figure 1 - Shear force as a function of ageing period.

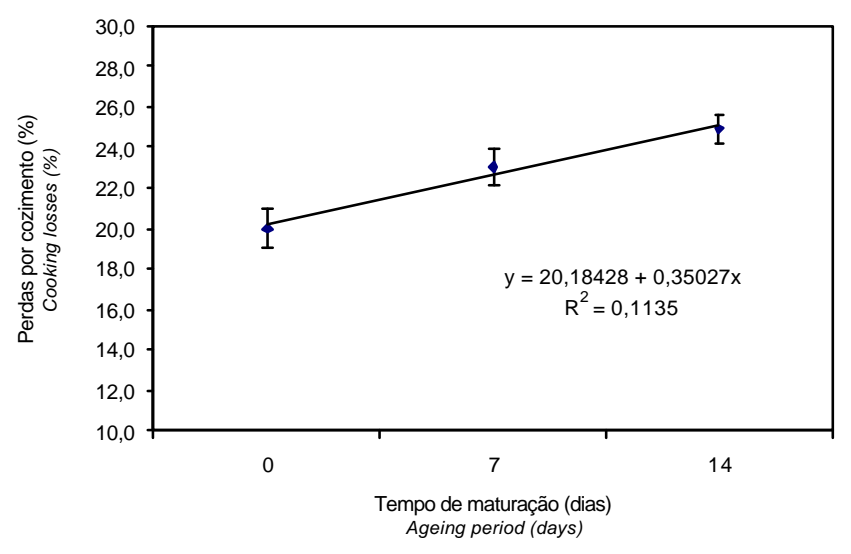

Figura 2 - Perdas por cocção em diferentes tempos de maturação.

Figure 2 - Cooking losses as a function of ageing period. ficativamente o desempenho, apesar de os animais tratados com SCAG terem apresentado ganho de peso médio $8 \%$ maior e ingestão média $9 \%$ menor, melhoran do a conversão alimentar, em média, de $2 \%$.

Por outro lado, Haaland et al. (1981), estudando o efeito da suplementação de gordura animal $(0,5$ ou $10 \%)$ protegida da degradação ruminal (formaldeído) sobre o desempenho de novilhos em confinamento, concluíram que a adição de $10 \%$ de gordura protegida reduziu a ingestão de MS, mas não alterou o ganho de peso nem a eficiência alimentar em relação à dieta controle (sem gordura). Em contrapartida, os animais alimentados com dietas suplementadas com nível intermediário de gordura protegida (5\%) consumiram mais, ganharam mais peso e foram mais eficientes que aqueles alimentados com a dieta com $10 \%$.

O número de protozoários do gênero Diplodinium foi menor $(\mathrm{P}=0,0005)$ nas dietas contendo SCAG. Foi observada interação $(\mathrm{P}<0,0001)$ em relação ao número de protozoários do gênero Ostracodinium, encontrados apenas na dieta contendo MGS sem SCAG $\left(0,32 \times 10^{4} ; \mathrm{P}<0,01\right)$.

As dietas contendo $\mathrm{SCAG}$ reduziram o número total de protozoários ciliados $(\mathrm{P}=0,0257)$, possivelmente em virtude de uma dissociação desse complexo no rúmen, liberando ácidos graxos insaturados, exercendo efeito tóxico aos protozoários ciliados. Redução do número de protozoários em dietas contendo fontes de gordura também foi observada por Ivan et al. (2001).

Contrário ao observado neste trabalho, Towne et al. (1990) não observaram alteração na quantidade total de protozoários ruminais de bovinos alimentados com dietas com $90 \%$ de concentrado contendo 3,5 a $4,0 \%$ de gordura de origem animal ou vegetal. Do mesmo modo, Valinote et al. (2005) não observaram efeito do fornecimento de $5 \%$ de SCAG (LAC 100) sobre o número de protozoários totais em comparação à dieta controle, sem SCAG.

Não foi observada diferença em relação ao PCQ, RC, GRPI e FIG entre animais tratados ou não com SCAG. Resultados semelhantes foram relatados por Haaland et al. (1981), que não observaram diferenças no PCQ, RC e EGS de animais alimentados com $10 \%$ de gordura animal protegida (formaldeído) em relação à dieta controle. No entanto, esses mesmos autores observaram AOL menor nos animais alimentados com dietas com gordura.

A adição de 1,2 ou 4,6\% de gordura animal na dieta de novilhos em fase de terminação não influenciou significativamente a maioria das características de carcaça, exceto a EGS, que foi maior nos animais alimentados com a dieta contendo 4,6\% de gordura (Bartle et al., 1994). O rendimento de carcaça e as gorduras renal, pélvica e cardíaca tenderam a aumentar com o maior teor de gordura na dieta. Em 
experimento complementar com níveis de alfafa (10,20 ou $30 \%$ ), esses mesmos autores observaram maior PCQ e das gorduras pélvica, renal e cardíaca nos animais que receberam nível mais alto de gordura na dieta $(4,6 \%)$.

Não foram observados efeitos do tipo de grão de milho ou dos SCAG sobre a força de cisalhamento (Figura 1) ou as perdas por cocção (Figura 2). Resultados semelhantes foram relatados por Patil et al. (1993), que não observaram efeito do nível de gordura na dieta sobre a força de cisalhamento ou as perdas por cocção. Aferri et al. (2005) e Margarido et al. (2005) também não observaram influência da adição de SCAG na dieta de novilhos sobre a força de cisalhamento.

A utilização de 5\% de SCAG também não influenciou significativamente as características de carcaça de novilhos em fase de terminação, conforme descrito por Aferri et al. (2005). No entanto, Margarido et al. (2005), testando a adição de 3\% de SCAG em dietas de baixo ou alto teor de concentrado, verificaram maior PCQ em dietas de alto concentrado com SCAG e maior RC $(1,5 \%)$ nas dietas contendo SCAG.

Efeito negativo sobre o peso de carcaça foi observado por Ngidi et al. (1990) com o aumento do nível de sais de cálcio na dieta, possivelmente em virtude da redução do consumo pelos animais alimentados com níveis mais elevados de SCAG, enquanto outras características de carcaça não foram influenciadas.

De acordo com Brandt \& Anderson (1990), em períodos de alimentação inferiores a 90 dias, vários trabalhos comprovam não haverinfluência da suplementação com gordura sobre o RC.

\section{Conclusões}

Animais alimentados com as dietas contendo milho grão úmido ingeriram menos alimento e foram mais eficientes que os alimentados com milho grão seco, no entanto, apresentaram redução no rendimento de carcaça. Para melhor avaliação da viabilidade de utilização do milho grão úmido, são necessários outros estudos que relacionem a redução dos custos de produção e o aumento da eficiência alimentar e do menor valor da carcaça (mais leve) no momento da comercialização. Os sais de cálcio de ácidos graxos aumentaram o ganho de peso e o consumo de alimento, mas não influenciaram a eficiência alimentar e as características de carcaça. A utilização de SCAG como alternativa para aumentar a densidade energética da dieta para bovinos Nelore confinados deve ser mais bem avaliada, em virtude do alto custo do produto.

\section{Literatura Citada}

AFERRI, G.; LEME, P.R.; SILVA, S.L. et al. Desempenho e características de carcaça de novilhos alimentados com dietas contendo diferentes fontes de lipídios. Revista Brasleira de Zootecnia, v.34, n.5, p.1651-1658, 2005.

AMERICAN MEAT SCIENCE ASOCIATION - AMSA. Research guidelines for cookery, sensory evaluation, and instrumental tenderness of fresh meat. Chicago: American Meat Science Association and National Live Stock and Meat Board, 1995. 49p.

BARTLE, S.J.; PRESTON, R.L.; MILLER, M.F. Dietary energy source and density: Effects of roughage source, roughage equivalent, tallow level, and steer type on feedlot performance and carcass characteristics. Journal of Animal Science, v.72, n.8, p.1943-1953, 1994.

BRANDT JR., R.T.; ANDERSON, S.J. Supplemental fat source affects feedlot performance and carcass traits of finishing yearling steers and estimated diet net energy value. Journal of Animal Science, v.68, p.2208-2216, 1990.

CHALUPA, W.; VECCHIARELLI, B.; ELSER, A.E. et al. Ruminal fermentation in vivo as influenced by long-chain fatty acid. Journal of Dairy Science, v.69, n.5, p.1293-1301, 1986.

DEHORITY, B.A. Classification and morphology of rumen protozoa. Wooster: Ohio Agricultural Research and Development Center, 1977. 82p.

FOX, D.G.; SNIFFEN, C.J.; O'CONNOR, J.D. et al. A net carbohydrate and protein system for evaluating cattle diets: III. Cattle requirements and diet adequacy. Journal of Animal Science, v.70, p.3578-3596, 1992.

GARRET, W.N.; YANG, Y.T.; DUNKLEY, W.L. et al. Energy utilization, feedlot performance and fatty acid composition of beef steers fed protein encapsulated tallow or vegetable oils. Journal of Animal Science, v.42, p.1522-1533, 1976.

HAALAND, G.L.; MATSUSHIMA, J.K.; JOHNSON, D.E. et al. Effect of replacement of corn by protected tallow in a cattle finishing diet on animal performance and composition. Journal of Animal Science, v.52, n.4, p.696-702, 1981.

HENDERSON, C. The effect of fatty acids on pure cultures of rumen bacteria. Journal of Agricultural Science, v.81, p.107-112, 1973

HENRIQUE, W.; LEME, P.R.; LANNA, D.P.D. et al. Avaliação do milho úmido com bagaço de cana ou silagem de milho na engorda de bovinos. 1. Desempenho animal e características de carcaça. In: REUNIÃO ANUAL DA SOCIEDADE BRASILEIRA DE ZOOTECNIA, 36., 1999, Porto Alegre. Anais... Porto Alegre:Sociedade Brasileira de Zootecnia, 1999. p.307.

HIBBERD, C.A.; WAGNER, D.G.; HINTZ, R.L. et al. Effect of sorghum grain variety and reconstitution on site and extent of starch and protein digestion in steers. Journal of Animal Science v.61, p.702-712, 1985.

IVAN, M.; MIR, P.S.; KOENING, K.M. et al. Effects of sunflower seed oil on rumen protozoa population and tissue concentration of conjugated linoleic acid in sheep. Small Ruminant Research, v.41, p.215-227, 2001.

LADELY, S.R.; STOCK, R.A.; GOEDEKEN, F.K. et al. Effect of corn hybrid and grain processing method on rate of starch disappearance and performance of finishing cattle. Journal of Animal Science, v.73, p.360-364, 1995

LANNA, D.P.; PACKER, I.U. Eficiência biológica e econômica de bovinos de corte. In: ALLENCAR, M.M.; FREITAS, A.R.; CRUZ, G.M. et al. (Eds.). WORKSHOP SOBRE QUALIDADE DA CARNE E MELHORAMENTO GENETICO DE BOVINOS, 1 , 1998, São Carlos. Anais... São Carlos: Embrapa/Fundepec. 1998. p.83-104.

LEME, P.R.; SILVA, S.L.; PEREIRA, A.S.C. et al. Utilização do bagaço de cana-de-açúcar em dietas com elevada proporção de 
concentrados para novilhos Nelore em confinamento. Revista Brasileira de Zootecnia, v.32, n.6, p.1786-1791, supl.1, 2003. MARGARIDO, R.C.C. Utilização da gordura protegida em rações a base de bagaço hidrolisado para bovinos em confinamento. Pirassununga: Faculdade de Zootecnia e Engenharia de Alimentos, 2005. 63p. Dissertação (Mestrado em Zootecnia). Faculdade de Zootecnia e Engenharia de Alimentos, 2005.

MENDOZA, G.D.; BRITTON, R.A.; STOCK, R.A. Influence of ruminal protozoa on site and extent of starch digestion and ruminal fermentation. Journal of Animal Science, v.71, p. $1572-1578,1993$.

MENDOZA, G.D.; BRITTON, R.A.; STOCK, R.A. Effect of feeding mixtures of high moisture corn and dry-rolled grain sorghum on ruminal fermentation and starch digestion. Small Ruminant Nutrition, v.32, p.113-118, 1999.

NGIDI, M.E.; LOERCH, S.C.; FLUHARTY, F.L.; PALMQUIST, D.L. Effects os calcium soaps of long-chain fatty acids on feedlot performance, carcass characteristics and ruminal metabolism of steers. Journal of Animal Science, v.68, p.2555-2565, 1990.

OWENS, F.N.; SECRIST, D.S.; HILL, W.J. et al. Effect of grain source and grain processing on performance of feedlot catlle: A review. Journal of Animal Science, v.75, p.868-879, 1997.

OWENS, F.N.; GARDNER, B.A. A review of the impact of feedlot management and nutrition on carcass measurements of feedlot cattle. Indianapolis: American Society of Animal Science, $1999.18 \mathrm{p}$.

PALMQUIST, D.L. The feeding value of fat. In: PALMQUIST, D.L. (Ed.) Use of fats in diets for lactating dairy cows. London: Butterworths, 1984. p.293-311.

PATIL, A.R.; GOETSCH, A.L.; LEWIS JR., P.K. et al. Effects of suplementing growing steers with high levels of partially hydrogenated tallow on feed intake, digestibility, live weight gain, and carcass characteristics. Journal of Animal Science, v.71, p.2284-2292, 1993.
STATISTICAL ANALYSES SYSTEM - SAS. SAS/STAT user's guide: statistics. 4.ed. Cary: 1997. v.2, 943p.

SCHAUFF, D.J.; CLARK, J.H. Effects of prilled fatty acids and calcium salts of fatty acids on rumen fermentation, nutrients digestibilities, milk production, and milk composition. Journal of Dairy Science, v.72, p.917-927, 1989.

SCOTT, T.L.; MILTON, C.T.; ERICKSON, G.E. et al. Corn processing method in finishing diets containing wet corn gluten feed. Journal of Animal Science, v. 81, p.3182-3190, 2003.

SIMAS, J.M. Processamento de grãos para rações de vacas leiteiras. In: SIMPÓSIO SOBRE PRODUÇÃO ANIMAL, 9., 1997, Piracicaba. Anais... Piracicaba: 1997. 184p.

STOCK, R.A.; BRINK, D.R.; BRANDT, R.T. et al. Feeding combinations of high moisture corn and dry corn to finishing cattle. Journal of Animal Science, v.65, p.282-289, 1987.

STOCK, R.A.; SINDT, M.H.; CLEALE IV, R.M. et al. High-moisture corn utilization in finishing cattle. Journal of Animal Science, v.69, p.1645-1656, 1991.

STREETER, M.N.; WAGNER, D.G.; OWENS, F.N. et al. Combinations of high-moisture harvest sorghum grain and dryrolled corn: effects on site and extent of digestion in beef heifers. Journal of Animal Science, v.67, p.1623-1633, 1989.

TOWNE, G.; NAGARAJA, T.G.; BRANDT JR., R.T. et al. Ruminal ciliated protozoa in cattle fed finishing diets with or without supplemental fat. Journal of Animal Science, v.68, p.21502155,1990

VALINOTE, A.C.; NOGUEIRA FILHO, J.C.M.; LEME, P.R. et al. Fontes de lipídeos e monensina na alimentação de novilhos Nelore e sua relação com a população de protozoários ciliados do rúmen. Revista Brasileira de Zootecnia, v.34, n.4, p.1418-1423, 2005. 